\title{
Assist Control Ventilation Versus Synchronized Mode Intermittent Mandatory Ventilation in Pediatric Intensive Care Unit
}

\author{
Nehad Ahmed Karam Abd El Fatah ${ }^{1}$, Dalia Abdul Latif Abdul Rahman', Ibrahim Saleh Farag Agaarib*2 \\ ${ }^{1}$ Department of Pediatrics, Faculty of Medicine, Zagazig University, Egypt \\ ${ }^{2}$ Department of Pediatrics, Faculty of Medicine, Sirte University, Libya \\ Corresponding author: Ibrahim Saleh Farag Agaarib, Mobile: 00218918939094, E-Mail: newscorpion84@gmail.com
}

\begin{abstract}
Background: Ventilator weaning consists of the gradual reduction of ventilatory support and the transfer of respiratory control and the work of breathing back to the patient, resulting in discontinuation of mechanical ventilation. Objective: The aim of this study was to compare between assisted controlled (AC) ventilation mode and synchronized intermittent mandatory ventilation (SIMV) mode for easy weaning in pediatric intensive care unit (PICU).

Subjects and methods: This was non-randomized control trial; 50 patients were selected and divided alternatively into two equal groups: an AC group (ACG) and an SIMV group (SIMVG). The patients were connected on SIMV or $\mathrm{AC}$ mode according to inclusion and exclusion criteria and follow up of the cases was done regarding ventilator settings, compliance of the patients, need of sedation, and progress of weaning process.

Results: the results revealed that there wass statistically non-significant difference between the studied groups regarding progress or weaning interruption. Larger percentage within both groups had progressive uninterrupted weaning. Conclusion: We found no evidence to support any clear-cut advantage of SIMV or AC in the acute management of respiratory failure, and we concluded that AC and SIMV could improve and fasten the weaning process and increase the success rate of weaning.
\end{abstract}

Keywords: Intermittent, Rate, SIMV, Synchronized, Ventilation, Weaning.

\section{INTRODUCTION}

Since its introduction into the modern PICUs, mechanical ventilation has undergone continuous evolution. Newer modes of mechanical ventilation have been introduced in an attempt to reduce barotrauma/volutrauma. No data exist so far to determine the ventilatory mode that provides the greatest benefit with the minimum risk of ventilator induced lung injury. Each model has precise indication which allows better application on one hand, while avoiding side effects on the other ${ }^{(1)}$. The most common ventilator weaning modes used in weaning children are pressure support ventilation, volume support ventilation, synchronized intermittent mandatory ventilation and a spontaneous breathing trial ${ }^{(2)}$. Synchronized intermittent mandatory ventilation is a combination modes by which patients receive mandatory (set) breaths synchronized with their breathing efforts and according to a pressure- or volumeselected mode. Patients breathe spontaneously with pressure support between ventilator breaths; this results in patient-ventilator synchrony ${ }^{(3)}$.

Synchronized intermittent mandatory ventilation (SIMV) has been the conventional mode of ventilation in many intensive care units (ICUs) around the world for decades. In SIMV, the physician sets the respiratory rate, tidal volume and levels of pressure support (PS), positive end-expiratory pressure (PEEP) and fractional inspired concentration of oxygen $\left(\mathrm{FiO}_{2}\right)$. Once set, the settings are static, until changed again by the operator on the basis of changing monitored parameters such as respiratory rate, pulse oximetry $\left(\mathrm{SpO}_{2}\right)$, end tidal $\mathrm{CO}_{2}\left(\mathrm{PetCO}_{2}\right)$ or intermittent arterial blood gas (ABG) measurements ${ }^{(4)}$.
In this mode, weaning often involves combined reduction of all of the above. A spontaneous breathing trial involves allowing the child to breathe spontaneously on minimal pressure support or through a T-piece attached to the ventilatory circuit. Each approach may be managed with or without written protocols, or with partial or fully automated ventilator loop algorithms ${ }^{(5)}$. Weaning refers to a gradual withdrawal of ventilatory support through a stepwise process, rather than extubation from full ventilatory support. For some children weaning may take weeks or months, and a few remain ventilator-dependent ${ }^{(6)}$.

In ACV mode, the breaths are patient- or time-triggered, flow-limited, and volume-cycled similar to SIMV mandatory breaths but unlike SIMV, all spontaneous breaths are assisted in the same manner. In this mode, the volume or pressure delivered in every breath will be the same, regardless of patient or time triggering ${ }^{(7)}$. Assist control ventilation $(\mathrm{A} / \mathrm{C})$, is a mode of ventilation where every spontaneous inspiratory effort is assisted with a mechanical breath ${ }^{(8)}$. The aim of this study was to compare between assisted controlled ventilation mode and synchronized intermittent mandatory ventilation mode for easy weaning in PICU.

\section{PATIENTS AND METHODS}

This study was a non-randomized control trial was carried out at PICU, Zagazig University Hospitals, from March 2019 until November 2019.

Target population: 50 children in pediatric intensive care unit.

- Group I (n=25) Patients treated with AC. 
- Group II ( $\mathrm{n}=25)$ Patients treated with SIMV.

Inclusion criteria: Patients admitted and mechanically ventilated for more than 48 hours and their guardians agreed to be included in the study.

Exclusion criteria: Patients or their legal guardians unable or unwilling to give informed consent, patients with chronic neuromuscular illness, chronic respiratory disease, air leak or obstructive airway disease, patients with complications of mechanical ventilation e.g., pneumothorax or ventilator acquired pneumonia that can lead to weaning delay, patients with increase work of breathing, agitation that may cause $\mathrm{CO}_{2}$ wash, children had been tracheostomized and/or patients admitted and mechanically ventilated for less than 48 hours.

Sample size: Assuming that the mean \pm SD of respiratory rate is $19.09 \pm 3$ in ACV group $17.06 \pm 2$ in SIMVG. So the sample size so (25 in each, group) using OPENEPI at power $80 \%$ and C.I $95 \%$

Sampling technique: This study was performed on systematic random sampling.

The patients were selected and divided alternatively into the two groups: an AC group (ACG) and an SIMV group (SIMVG); using bellavista, dragger and Raphael mechanical ventilator machines. The patients were connected alternatively on SIMV and AC mode according to inclusion and exclusion criteria and follow up of the cases was done regarding ventilator settings, compliance of the patients, need of sedation, progress of weaning process. Regarding the SIMV mode; the weaning process was started according to treating physician decision and started as protocolized recorded data by reducing PIP ( 2 by 2 ), $\mathrm{FiO}_{2}$ ( 5 by 5 ), PEEP ( 1 by 1 ) and lastly rate 2 by 2 till we reached the appropriate least frequency according to patient age, then the patients were turned to pressure support ventilation (P.S) mode till extubation.

A protocol was filled out with identification details, age, date of admission, cause of admission, indication for ventilatory support, ventilator used, date weaning started, time of weaning, success or failure of weaning (and reason for failure), time and duration of mechanical ventilation. Before data collection began, all daytime and on-call staff were trained to fill out this study protocol.
Regarding assist control mode, the patient was connected according to our inclusion and exclusion criteria; the initial settings were adjusted according to treating physician and patient condition then the decision of weaning if taken, by the treating physician, the setting was reduced $\mathrm{FiO}_{2}$ ( 5 by 5 ), rate ( 2 by 2 ) till the patient become on P.S. only then turned to P.S mode for 24 hours, Spontaneous breathing trial was done for our patient then extubation decision.

\section{Ethical approval:}

An informed verbal consent from all participants' gurdians was taken and confidentiality of information was assured. An official written administrative permission letter was obtained from dean of Faculty of Medicine, Zagazig University Hospitals, head of Pediatric Department and manager of Pediatric Hospital. The title and objectives of the study were explained to them to ensure their cooperation. Permission from the Faculty of Medicine Ethical Committee was also obtained and approval from institutional review board (Zu-IRB) was taken.

\section{Statistical analysis}

Analysis of data was done using Statistical Program for the Social Sciences version 20 (SPSS Inc., Chicago, IL, USA). Quantitative variables were described in the form of median, range, mean and standard deviation. Qualitative variables were described as number and percent. In order to compare parametric quantitative variables between two groups, Student $t$ test was performed. Mann-Whitney tests and Wilcoxon matched pairs test were used to compare non-parametric quantitative variables. Qualitative variables were compared using chi-square $\left(\mathrm{X}^{2}\right)$ test or Fisher's exact test when frequencies were below five. Pearson correlation coefficients were used to assess the association between two normally distributed variables. When a variable was not normally distributed, A P value $<0.05$ is considered significant.

\section{RESULTS}

There was statistically non-significant difference between the studied groups regarding age and gender (Table 1).

Table (1): Comparison between the studied groups regarding demographic characteristics.

\begin{tabular}{||c|c|c|c|c||}
\hline \multirow{2}{*}{$\begin{array}{c}\text { Demographic } \\
\text { characteristics }\end{array}$} & AC mode & SIMV group & \multicolumn{2}{|c|}{ Test } \\
\cline { 2 - 4 } & $\begin{array}{c}\text { N=25 [Number (\%)] or } \\
\text { Median (range) }\end{array}$ & $\begin{array}{c}\text { N=25 [Number (\%)] or } \\
\text { Median (range) }\end{array}$ & \multirow{2}{*}{$\mathbf{z}$} \\
\hline \hline $\begin{array}{l}\text { Gender: } \\
\text { Male }\end{array}$ & $13(52)$ & $\begin{array}{c}19(76) \\
6(24)\end{array}$ & 3.125 & 0.077 \\
Female & $12(48)$ & $0.75(0.17-11)$ & -1.886 & 0.059 \\
\hline $\begin{array}{l}\text { Age (years): } \\
\text { Median (range) }\end{array}$ & $2(0.17-14)$ & & \multicolumn{2}{||}{} \\
\hline
\end{tabular}

Z Mann Whitney test,

There was statistically non-significant difference between the studied groups regarding cause of admission.

Larger percentage within both groups were admitted secondary to respiratory causes (Table 2). 
Table (2): Comparison between the studied groups regarding cause of admission to PICU.

\begin{tabular}{|c|c|c|c|c|}
\hline \multirow{3}{*}{ Cause of admission } & \multicolumn{2}{|c|}{ Groups } & \multicolumn{2}{|c|}{ Test } \\
\hline & AC mode & SIMV group & \multirow[b]{2}{*}{$\chi^{2}$} & \multirow[b]{2}{*}{$\mathbf{p}$} \\
\hline & $\begin{array}{c}\mathrm{N}=25 \\
{[\mathrm{Number}(\%)]}\end{array}$ & $\begin{array}{c}\mathrm{N}=25 \\
{[\text { Number }(\%)]}\end{array}$ & & \\
\hline \multirow{6}{*}{$\begin{array}{l}\text { Cardiac causes } \\
\text { Miscellaneous: (Hematological, } \\
\text { drug anaphylaxis, tumors, } \\
\text { drowning) } \\
\text { Neurological causes } \\
\text { Renal causes } \\
\text { Respiratory causes }\end{array}$} & $0(0)$ & $3(12)$ & \multirow{6}{*}{7.758} & \multirow{6}{*}{0.101} \\
\hline & $3(12)$ & $0(0)$ & & \\
\hline & & & & \\
\hline & $9(36)$ & $5(20)$ & & \\
\hline & $2(8)$ & $2(8)$ & & \\
\hline & $11(44)$ & $15(60)$ & & \\
\hline
\end{tabular}

There was statistically significant difference between the studied groups regarding apnea and hypoxic respiratory failure as a cause for ventilation (all patients with apnea belonged to AC mode while all that with hypoxia underwent SIMV mode) (Table 3).

Table (3): Comparison between the studied groups regarding cause of mechanical ventilation.

\begin{tabular}{||l|c|c|c|c||}
\hline \multirow{4}{*}{ Cause of ventilation } & \multicolumn{2}{|c|}{ Groups } & \multicolumn{2}{c||}{ Test } \\
\cline { 2 - 3 } & AC mode & SIMV group & \multirow{2}{*}{} & \multirow{2}{*}{ P } \\
\cline { 2 - 5 } & $\begin{array}{c}\text { N=25 } \\
\text { [Number (\%)] }\end{array}$ & $\begin{array}{c}\text { N=25 } \\
\text { [Number (\%)] }\end{array}$ & & \\
\hline Abnormal breathing & $6(24)$ & $5(20)$ & 0.117 & 0.732 \\
Apnea & $19(76)$ & $0(0)$ & Fisher & $<0.001^{* *}$ \\
Cyanosis & $0(0)$ & $3(12)$ & Fisher & 0.235 \\
Hypercapnic respiratory failure & $0(0)$ & $4(16)$ & Fisher & 0.11 \\
Hypoxic RF & $0(0)$ & $13(52)$ & Fisher & $<0.001^{* *}$ \\
\hline
\end{tabular}

$* * \mathrm{p} \leq 0.001$ is statistically highly significant

There was statistically non-significant difference between the studied groups regarding time or duration of ventilation. Larger percentage within both groups had been ventilated on admission. Duration of ventilations, median duration in both groups was 6 days (Table 6 ).

Table (4): Comparison between the studied groups regarding time and duration of ventilation.

\begin{tabular}{|c|c|c|c|c|}
\hline \multirow{3}{*}{ Ventilation } & \multicolumn{2}{|c|}{ Groups } & \multicolumn{2}{|c|}{ Test } \\
\hline & AC mode & SIMV group & \multirow[b]{2}{*}{$\chi^{2} / Z$} & \multirow[b]{2}{*}{$\mathbf{p}$} \\
\hline & $\begin{array}{l}\mathrm{N}=25 \text { [Number }(\%) \\
\text { or as written] }\end{array}$ & $\begin{array}{c}\mathrm{N}=25 \text { [Number (\%) } \\
\text { or as written] }\end{array}$ & & \\
\hline $\begin{array}{l}\text { Time of ventilation: } \\
\text { On admission } \\
\text { During the first day } \\
\text { Second day } \\
\text { Third day } \\
\text { Fourth day } \\
\text { Sixth day }\end{array}$ & $\begin{array}{c}21(84) \\
0(0) \\
3(12) \\
1(4) \\
0(0) \\
0(0)\end{array}$ & $\begin{array}{c}16(64) \\
1(4) \\
4(16) \\
2(8) \\
1(4) \\
1(4)\end{array}$ & 1.359 & 0.244 \\
\hline $\begin{array}{l}\text { Duration (days): } \\
\text { Mean } \pm \text { SD } \\
\text { Median (range) }\end{array}$ & $\begin{array}{c}8.88 \pm 4.85 \\
6(4-18) \\
\end{array}$ & $\begin{array}{c}7.16 \pm 4.04 \\
6(4-15) \\
\end{array}$ & $(-1.587)$ & 0.115 \\
\hline
\end{tabular}

There was statistically non-significant difference between the studied groups regarding time or days of weaning (Table 5). 
Table (5): Comparison between the studied groups regarding time and days of weaning.

\begin{tabular}{|c|c|c|c|c|}
\hline \multirow{3}{*}{ Weaning } & \multicolumn{2}{|c|}{ Groups } & \multicolumn{2}{|c|}{ Test } \\
\hline & AC mode & SIMV group & & \\
\hline & $\mathrm{N}=25$ & $\mathrm{~N}=25$ & $\mathbf{Z}$ & $\mathbf{p}$ \\
\hline $\begin{array}{l}\text { Time of weaning (days): } \\
\text { Mean } \pm \text { SD } \\
\text { Median (range) }\end{array}$ & $\begin{array}{c}3.44 \pm 2.18 \\
3(2-10)\end{array}$ & $\begin{array}{c}2.64 \pm 0.7 \\
3(2-4)\end{array}$ & -1.125 & 0.26 \\
\hline $\begin{array}{l}\text { Weaning days: } \\
\text { Mean } \pm \text { SD } \\
\text { Median (range) }\end{array}$ & $\begin{array}{c}5.48 \pm 3.98 \\
4(2-15)\end{array}$ & $\begin{array}{c}4.56 \pm 3.68 \\
3(1-13)\end{array}$ & -1.39 & 01.65 \\
\hline
\end{tabular}

There was statistically significant difference between the studied groups regarding $\mathrm{FiO}_{2}$ and PEEP (Table 6).

Table (6): Comparison between the studied groups regarding respiratory rate and respiratory support parameters on admission.

\begin{tabular}{|c|c|c|c|c|}
\hline \multirow{3}{*}{ Respiratory support data } & \multicolumn{2}{|c|}{ Groups } & \multicolumn{2}{|c|}{ Test } \\
\hline & AC mode & SIMV group & $t / Z$ & $\mathbf{p}$ \\
\hline & $\mathrm{N}=25$ & $\mathrm{~N}=25$ & $1 / 2$ & $\mathbf{p}$ \\
\hline $\begin{array}{l}\text { Respiratory rate (/minute): } \\
\text { Mean } \pm \text { SD } \\
\text { Median (range) }\end{array}$ & $\begin{array}{c}37.4 \pm 8.91 \\
25-55\end{array}$ & $\begin{array}{c}35.52 \pm 7.99 \\
22-50\end{array}$ & $\mathrm{t}(\mathbf{0 . 7 8 5})$ & 0.436 \\
\hline $\begin{array}{l}\mathrm{FiO}_{\mathbf{2}}(\boldsymbol{\%}) \mathbf{:} \\
\text { Mean } \pm \text { SD } \\
\text { Median (range) }\end{array}$ & $\begin{array}{l}53.56 \pm 27.68 \\
50(21-100)\end{array}$ & $\begin{array}{c}68.92 \pm 18.45 \\
65(40-95) \\
\end{array}$ & $\mathrm{Z}(-\mathbf{2 . 1 1 8})$ & $0.034 *$ \\
\hline 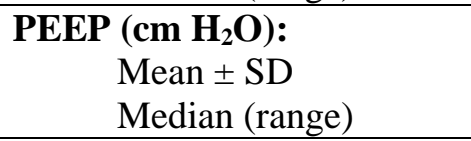 & $\begin{array}{c}5.34 \pm 1.01 \\
4-8 \\
\end{array}$ & $\begin{array}{c}5.96 \pm 1.36 \\
4-8 \\
\end{array}$ & $\mathrm{t}(1.830)$ & 0.074 \\
\hline 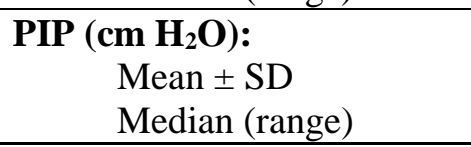 & $\begin{array}{c}21.24 \pm 6.03 \\
12-30 \\
\end{array}$ & $\begin{array}{c}22.52 \pm 2.87 \\
18-28 \\
\end{array}$ & $\mathrm{t}(-0.958)$ & 0.343 \\
\hline
\end{tabular}

There was statistically significant difference between the studied groups regarding $\mathrm{PaCO}_{2}$. (Table 7).

Table (7): Comparison between the studied groups regarding initial ABG.

\begin{tabular}{|c|c|c|c|c|}
\hline \multirow{3}{*}{$\begin{array}{l}\text { Arterial blood gases } \\
\text { parameters }\end{array}$} & \multicolumn{2}{|c|}{ Groups } & \multicolumn{2}{|c|}{ Test } \\
\hline & AC mode & SIMV group & & \\
\hline & $\mathrm{N}=25$ & $\mathrm{~N}=25$ & $\mathbf{Z} / \mathbf{t}$ & $\mathbf{p}$ \\
\hline $\begin{array}{c}\left.\mathbf{P a O}_{2} \mathbf{m m H g}\right): \\
\text { Mean } \pm \text { SD } \\
\text { Median }\end{array}$ & $\begin{array}{c}80.19 \pm 4.9 \\
79\end{array}$ & $\begin{array}{c}71.86 \pm 6.89 \\
60\end{array}$ & -1.943 & 0.052 \\
\hline $\begin{array}{l}\text { PH: } \\
\quad \begin{array}{l}\text { Mean } \pm \text { SD } \\
\text { range }\end{array}\end{array}$ & $\begin{array}{l}7.32 \pm 0.12 \\
7.08-7.54\end{array}$ & $\begin{array}{l}7.31 \pm 0.12 \\
7.1-7.53\end{array}$ & $\mathrm{t}(0.24)$ & 0.812 \\
\hline $\begin{array}{c}\mathbf{P a C O}_{2}(\mathbf{m m H g}): \\
\text { Mean } \pm \text { SD } \\
\text { Median }\end{array}$ & $\begin{array}{c}60.58 \pm 22.17 \\
55 \\
\end{array}$ & $\begin{array}{c}47.79 \pm 17.11 \\
44 \\
\end{array}$ & -2.106 & $0.035^{*}$ \\
\hline
\end{tabular}

There was statistically non-significant difference between the studied groups regarding progress or weaning interruption (larger percentage within both groups had progressive uninterrupted weaning) (Table 8). 
Table (8): Comparison between the studied groups regarding weaning course.

\begin{tabular}{|c|c|c|c|c|}
\hline \multirow{3}{*}{ Weaning } & \multicolumn{2}{|c|}{ Groups } & \multicolumn{2}{|c|}{ Test } \\
\hline & AC mode & SIMV group & \multirow[b]{2}{*}{$\chi^{2}$} & \multirow[b]{2}{*}{$\mathbf{p}$} \\
\hline & $\begin{array}{c}\mathrm{N}=25 \\
{[\text { Number }(\%)]}\end{array}$ & $\begin{array}{c}\mathrm{N}= \\
\text { [Number (\%)] }\end{array}$ & & \\
\hline $\begin{array}{l}\text { Progress : } \\
\text { Non progressive } \\
\text { Progressive }\end{array}$ & $\begin{array}{c}7(28) \\
18(72)\end{array}$ & $\begin{array}{l}7(28) \\
18(72)\end{array}$ & 0 & 1 \\
\hline $\begin{array}{l}\text { Interruption: } \\
\text { Interrupted } \\
\text { Uninterrupted }\end{array}$ & $\begin{array}{l}11(44) \\
14(56)\end{array}$ & $\begin{array}{l}7(28) \\
18(72)\end{array}$ & 1.389 & 0.239 \\
\hline
\end{tabular}

\section{DISCUSSION}

In the present study we assessed the demographic characteristics and found that there was statistically non-significant difference between the studied groups regarding age and gender.

In agreement with our findings, the study of de Moraes et al. ${ }^{\left({ }^{9}\right)}$ that aimed to compare intermittent mandatory ventilation (IMV) with synchronized intermittent mandatory ventilation plus pressure support $(\mathrm{SIMV}+\mathrm{PS})$ in terms of time on mechanical ventilation, duration of weaning and length of stay in a pediatric intensive care unit (PICU) and revealed that their groups did not differ statistically in terms of age, sex or disease severity as assessed by the PRISM score.

In the present study we assessed the cause of ventilation among the participant children and found that there was statistically significant difference between the studied groups regarding apnea and hypoxic respiratory failure where all patients with apnea belonged to AC mode while all those with respiratory failure underwent SIMV mode.

In agreement with our results, previous study of Bhori et al. ${ }^{(1)}$ found that $15.93 \%$ (72/452) of patients were admitted to PICU and received mechanical ventilation. The percentage of pediatric patients mechanically ventilated in different PICU's varied from $14-60 \%$. The most common indication for mechanical ventilation in this study was respiratory failure $(22.22 \%)$ either due to affection of the central nervous system or the respiratory system. Several reports mention respiratory failure due to respiratory illness was the most

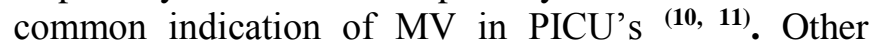
studies reported acute neurological illnesses as the most common reason for MV in PICU's ${ }^{(2,12)}$.

In our study we revealed that there was statistically non-significant difference between the studied groups regarding cause of admission. Larger percentage within both groups (44\% and $60 \%$ for AC and SIMV modes respectively) had been admitted secondary to respiratory causes.

In accordance with our findings, the study of Valavi et al. ${ }^{(13)}$ reported that among the 688 patients enrolled in the study, $55.6 \%$ were male and the mean patient age was 2.7 years. The most common causes of admission were pneumonia $(22.9 \%)$, bronchiolitis (8.6\%), and septicemia (7.9\%).

In addition to above findings we assessed the duration of ventilation among the participants in the two groups and found that there was statistically nonsignificant difference between the studied groups regarding time or duration of ventilation. Larger percentage within both groups had been ventilated on admission. Concerning duration of ventilations, median duration in both groups was 6 days, in accordance with our findings; the study of Bhori et al. ${ }^{(\mathbf{1})}$ reported that the mean duration of mechanical ventilation of the patients was 4.2 \pm 4.32 days while another study of Kendirli $\boldsymbol{e t}$ al. (11) reported that the period of mechanical ventilation in their study was $18.8 \pm 14.1$ days.

Despite its life saving advantages, mechanical ventilation is associated with physiologic and mechanical complications. Complications prolong the duration the MV and the hospital stay. Thus, increasing the health care cost in terms of emotional and economic burden on the patient and its family, and man hours and machine hours to the provider. It puts strain on the already burdened health care system in developing countries. Alternatives must be tried before proceeding to invasive MV, wherever feasible ${ }^{(1)}$. The present study reported that there was statistically non-significant difference between the studied groups regarding complications during weaning ( $72 \%$ within each group passed uncomplicated).

Furthermore, the current study assessed time and days of weaning among the patients in the studied groups, and revealed that there was statistically nonsignificant difference between the studied groups regarding time or days of weaning.

Like our findings, the study of Adrienne et al. (14) that aimed to evaluate whether weaning protocols are superior to standard care (no defined protocol) for infants and children with acute illnesses requiring mechanical ventilator support and whether a volume support weaning protocol using continuous automated adjustment of pressure support by the ventilator (i.e., VSV) is superior to manual adjustment of pressure support by clinicians, in which patients were randomized to a PSV protocol $(n=62)$, VSV protocol 
$(n=60)$, or no protocol $(n=60)$, and reported that the mean weaning times for the three studied groups were $3.3,2.5$, and 3.2 days, respectively. The medians were $1.6,1.8$, and 2.0 days. Weaning times did not differ significantly between treatment groups $(\mathrm{P}=0.75)$

Limiting the duration of airway intubation and mechanical ventilator support to the shortest possible time is of utmost importance for reducing risk of nosocomial infection, tracheal irritation and injury, and sedative dependency. Shortening the duration of mechanical ventilator support should also decrease ICU length of stay and associated costs. The prevalent philosophy is that it is necessary to gradually wean children experiencing respiratory failure from the mechanical ventilator to retrain their respiratory muscle strength ${ }^{(14)}$.

Once the patient is ready to initiate the weaning process, it requires the appropriate settings on the ventilator. The parameters include tidal volume, respiratory rate, positive end-expiratory pressure (PEEP), the fraction of inspired oxygen $\left(\mathrm{FiO}_{2}\right)$, and, if used, the pressure support setting. After the initiation of mechanical ventilation, it is best practice to obtain an arterial blood gas within 60 minutes and to titrate the ventilator settings accordingly ${ }^{(\mathbf{1 5})}$.

In the study on the hand, the results revealed that there was statistically significant difference between the studied groups regarding $\mathrm{FiO}_{2}$, and PEEP (significantly higher in patients underwent SIMV mode because in AC mode group we don't need high $\mathrm{FiO}_{2}$ and PEEP), and there was statistically non-significant difference between the studied groups regarding PIP and respiratory rate.

Also in the current study we revealed that there was statistically significant difference between the studied groups regarding $\mathrm{PaCO}_{2}$ and there was statistically non-significant difference between the studied groups regarding $\mathrm{PH}$ and $\mathrm{PaO}_{2}$ and this can be explained by that the cause of use of AC mode ventilation was apnea.

The ABG parameters obtained after initiation of mechanical ventilation were compared between the ventilator modes in the study of Mathews and Unnikrishnan ${ }^{(7)}$ and they reported that oxygenation was better in the SIMV-PS group with a significantly higher $\mathrm{PaO} 2 / \mathrm{FiO}_{2}$ ratio $(\mathrm{P}=0.02)$ in the $\mathrm{SIMV}+\mathrm{PSV}$ group than $\mathrm{ACV}$ group after the initiation of mechanical ventilation. The study reported that $\mathrm{pH}$ in the SIMV + PSV group was $7.43(7.29,7.46)$ and in ACV group was 7.31 (7.21, 7.39) ( $\mathrm{p}$ value $\left.=0.008^{*}\right)$, and $\mathrm{PaCO}_{2}(\mathrm{~mm} \mathrm{Hg})$ was 32 $(28,38)$ in the SIMV + PSV group and $40(33,47)$ in AC group, so ventilation was also better in the SIMV + PSV group as evidenced by a lower $\mathrm{PaCO} 2(\mathrm{P}=0.033)$ and a higher $\mathrm{pH}(\mathrm{P}=0.008)$ as compared to $\mathrm{ACV}$ group were significantly high.

In the present study we compared between the studied groups regarding weaning course, and found that there was statistically non-significant difference between the studied groups regarding progress or weaning interruption (larger percentage within both groups had progressive uninterrupted weaning, and there was statistically non-significant difference between the studied groups regarding outcome of weaning during weaning ( $72 \%$ within each group underwent successful weaning).

Patients undergoing mechanical ventilation (MV) were traditionally sedated with benzodiazepines and/or propofol to make them comfortable and to avoid pain and anxiety. However, sedation may have negative consequences, such as prolongation of MV and weaning period with consequent higher costs. The risk of complications such as ventilator-associated pneumonia may also be increased. Early deep sedation, however it is achieved, was associated with longer time to extubation and increased mortality ${ }^{(16)}$.

\section{CONCLUSION}

We found that AC and SIMV modes could improve and fasten the weaning process and increase the success rate of weaning. Careful assessment of individual patients any indicate which patient might benefit from each modality of support.

\section{REFERENCES}

1. Bhori N, Ghate S, Chhajed P (2017): A study of mechanical ventilation in children. Int $\mathrm{J}$ Contemp Pediatr., 4: 2088-92.

2. Wolfler A, Calderoni E, Ottonello G et al. (2011): Daily practice of mechanical ventilation in Italian pediatric intensive care units: a prospective survey. Pediatr Crit Care Med., 12(2):141-6.

3. Gallagher $\mathbf{J}$ (2016): Invasive mechanical ventilation (through an artificial airway): volume and pressure modes. AACN Procedure Manual for High Acuity, Progressive, and Critical Care-E-Book, Pp. 227. https://www.elsevier.com/ data/assets/pdf_file/0017/271007/ch0029.pdf

4. Abutbul A, Sviri S, Zbedat $W$ et al. (2014): A prospective comparison of the efficacy and safety of fully closed-loop control ventilation (Intellivent-ASV) with conventional ASV and SIMV modes. Southern African Journal of Critical Care (Online), 30(1): 28-32.

5. Brown B, Roberts J (2016): Principles of artificial ventilation. Anaesthesia \& Intensive Care Medicine, 17(3): 120-132.

6. Blackwood B, Alderdice F, Burns $\mathrm{K}$ et al. (2010): Protocolized versus non-protocolized weaning for reducing the duration of mechanical ventilation in critically ill adult patients. https://pubmed.ncbi.nlm.nih.gov/20464747/

7. Mathews C, Unnikrishnan R (2017): Comparison of Synchronised Intermittent Mandatory Ventilation with Pressure Support versus Assist Control mode of ventilation on time to extubation. Ind J Resp Care, 6(1): 781-5.

8. Blanch L, Villagra A, Sales B et al. (2015): Asynchronies during mechanical ventilation are 
associated with mortality. Intensive Care Medicine, 41(4): 633-641.

9. de Moraes A, Rossano C, Mário F et al. (2009): Comparison between intermittent mandatory ventilation and synchronized intermittent mandatory ventilation with pressure support in children Marcos, J Pediatr (Rio J), 85(1):15-20.

10. Farias J, Frutos F, Esteban A et al. (2004): What is the daily practice of mechanical ventilation in pediatric intensive care units? A multicentre study. Intensive Care Med., 30(5):918-25.

11. Kendirli T, Kavaz A, Yalaki $Z$ et al. (2006): Mechanical ventilation in children. Turk J Pediatr., 48(4):323-7.

12. Mukhtar B, Siddiqui N, Haque A (2014): Clinical characteristics and immediate outcome of children mechanically ventilated in a Pediatric Intensive Care Unit. Pak J Med Sci., 30(5):927-30.
13. Valavi E, Aminzadeh M, Shirvani E et al. (2018): The main causes of mortality in pediatric intensive care unit in south west of Iran, Zahedan J Res Med Sci., 20(4):63006.

14. Adrienne R, Wypij D, Venkataraman S et al. (2002): Effect of mechanical ventilator weaning protocols on respiratory outcomes in infants and children: A randomized controlled trial. Journal of the American Medical Association, 288: 2561-8.

15. McConnell R, Kerlin M, Schweickert W et al. (2016): Using a Post-intubation checklist and time out to expedite mechanical ventilation monitoring: Observational Study of a Quality Improvement Intervention. Respir Care, 7:902-12.

16. Jakob S, Ruokonen E, Grounds R et al. (2012): Dexmedetomidine for long-term sedation investigators dexmedetomidine vs midazolam or propofol for sedation during prolonged mechanical ventilation: two randomized controlled trials. JAMA., 307:1151-1160. 